\title{
O conceito de
} translinguagem e suas implicações para os estudos sobre bilinguismo e multilinguismo

\author{
Ana Paula SCHOLL (1)
}

Universidade Federal do Rio Grande do Sul (UFRGS)

\section{RESUMO}

Na sua conferência para a Abralin ao Vivo, Li Wei oferece um panorama sobre o que é translinguagem e quais são as suas implicações teóricas e metodológicas para os estudos sobre bilinguismo e multilinguismo. Para o conferencista, usar translinguagem é deslocar-se entre diferentes estruturas e sistemas linguísticos, incluindo diferentes modalidades, e ir também além deles. O construto compreende todo o conjunto das práticas linguísticas dos multilíngues, sendo um ato de natureza transformadora. Assim, através do uso da translinguagem, bilíngues e multilíngues podem

EDITADO POR ter a oportunidade de usar todo o seu repertório linguístico para compreender e produzir sentidos. É a partir dessa concepção que o apresentador traz provocações para que se passe a pensar a comunicação multilíngue como uma prática bastante complexa, o que gera novas questões em relação a assuntos fundamentais relacionados à comunicação humana.

\section{ABSTRACT}

In his conference for Abralin ao Vivo, Li Wei offers an overview of the concept of translanguaging and its theoretical and methodological implications for research on bilingualism and multilingualism. According to the lecturer, using translanguaging is moving between different linguistic structures and systems, including different modalities, and going beyond them. The term comprises the entire set of multilingual linguistic practices, and, for this reason, is a transformative act. Thus, the concept of 


\section{REVISTA DA ABRALIN}

translanguaging enables bilingual and multilingual individuals to employ their complete linguistic repertoire in order to understand and produce meaning. From this point of view, the presenter urges people to start thinking about multilingual communication as a complex practice, which raises new questions regarding fundamental topics related to human communication.

PALAVRAS-CHAVE

Translinguagem. Bilinguismo. Multilinguismo.

KEYWORDS

Translanguaging. Bilingualism. Multilingualism.

A conferência Trans-Ing Language and Cognition: Debates and Directions of Translanguaging Research proferida por Li Wei aconteceu no dia 27/07/2020. A palestra, disponível no canal da Abralin no Youtube, foi mediada pela Dra. Caroline Tagg, professora de Linguística Aplicada e Língua Inglesa na Open University e secretária da Associação Britânica de Linguística Aplicada (BAAL).

Li Wei é coordenador de Linguística Aplicada e diretor do Centro de Linguística Aplicada da University College London e o principal editor da revista International Journal of Bilingualism and Applied Linguistics Review. Seus principais interesses de pesquisa englobam o multilinguismo e as práticas multilíngues, dando atenção especial à translinguagem. É editor de livros de grande sucesso sobre bilinguismo, como The Bilingualism Reader (2000) e The Blackwell Guide to Research Methods in Bilingualism and Multilingualism (2008). O seu trabalho sobre translinguagem com Ofelia García deve ser destacado, incluindo o indispensável livro Translanguaging: Language, Bilingualism and Education (2014). Na sua conferência para a Abralin ao Vivo, o linguista sintetiza os principais conceitos relacionados à translinguagem e promove uma discussão sobre as suas implicações teóricas e metodológicas para os estudos sobre bilinguismo e multilinguismo.

O termo translinguagem tem aparecido de forma mais consistente na última década, apesar de ter sido cunhado nos anos 1990 e ter sido usado em diferentes áreas desde então. A origem da palavra é atribuída a Colin Baker (2001), que a utilizou para se referir à prática pedagógica de empregar as duas línguas do bilíngue na sala de aula de forma fluida e dinâmica. Através dessa prática, os alunos poderiam receber a instrução em uma de suas línguas e realizar a tarefa na outra, por exemplo. Desde então, esse conceito tem sido adotado por diversos pesquisadores para caracterizar as práticas linguísticas de indivíduos bilíngues e multilíngues. A popularização e a expansão do termo se deram em grande parte pelos estudos de Ofelia García que, em 2009, definiu translinguagem como as múltiplas práticas discursivas que os bilíngues usam para dar sentido aos seus mundos bilíngues. 


\section{REVISTA DA ABRALIN}

O conceito de translinguagem tem como base os estudos sobre languaging, que postulam que a linguagem humana é heterogênea e envolve processos distintos. A ideia é que a linguagem seja repensada e não mais considerada uma entidade formal, mas uma organização múltipla de processos que permitem interações que transcendem dinâmicas e práticas históricas e culturais. Através dessa perspectiva, não há divisões entre o que é linguístico, extralinguístico ou paralinguístico na comunicação humana.

Além de nos encorajar a pensar na linguagem humana como uma prática heterogênea, a perspectiva da translinguagem também traz uma problematização muito interessante em relação à ideia de "línguas nomeadas" (como português ou inglês, por exemplo). Na sua fala, Li Wei chama a atenção para o fato de que línguas nomeadas são conceitos político-culturais que são associados com uma ideologia de que cada nação possui apenas uma língua. Dessa forma, a invenção dos estados-nação também gerou a noção de monolinguismo. Já a proposta da translinguagem difere dessa concepção e vai além dos limites de línguas nomeadas. É importante ressaltar que o conceito de translinguagem não nega a existência de línguas nomeadas, apenas destaca que as línguas são entidades histórica, ideológica e politicamente definidas.

Tendo essas considerações em mente, a translinguagem é abordada pelo conferencista como uma teoria prática, isto é, a teoria é baseada na prática e, por sua vez, também serve à prática. Dessa forma, Li Wei afirma que as práticas linguísticas que o interessam são as do bilinguismo e do multilinguismo, ou seja, entender como as pessoas produzem sentidos no dia a dia e compreendem o mundo quando elas têm elementos de duas ou mais línguas. Para o linguista, usar translinguagem é deslocar-se entre diferentes estruturas e sistemas linguísticos, incluindo diferentes modalidades, e também além deles. Alguns exemplos usados para demonstrar como essas práticas acontecem são um diálogo entre idosos de Singapura que usam elementos de diferentes línguas nomeadas e não nomeadas para produzirem sentidos de forma fluida e dinâmica e a comunicação digital, que usa componentes de línguas nomeadas, bem como imagens e emojis, para produzir sentidos de forma integrada. A translinguagem compreende todo o conjunto das práticas linguísticas dos multilíngues, sendo assim um ato de natureza transformadora.

Para Li Wei, o conceito de translinguagem é transformador pois ele cria o espaço social para que os indivíduos bi/multilíngues reúnam diferentes aspectos da sua experiência, bem como suas capacidades físicas e cognitivas, na produção de sentidos. Dentro dessa abordagem, um bilíngue/multilíngue é alguém que tem consciência da existência de línguas nomeadas como entidades políticas, adquire algumas de suas características funcionais e consegue usá-las na comunicação de forma fluida, empregando assim o seu repertório linguístico completo, sem as marcações sociais e políticas de línguas nomeadas.

É por dar conta dessas práticas que o apresentador gosta do termo translinguagem. O conceito possibilita o entendimento de diferentes fenômenos linguísticos que transcendem os limites das línguas nomeadas, bem como os limites entre linguagem e outros meios de produção de sentidos. Além disso, o conceito de translinguagem nos convida a repensar a comunicação multilíngue como um tipo de discurso mais complexo, que usa diversas variedades e registros linguísticos e múltiplas 


\section{REVISTA DA ABRALIN}

modalidades e mídias para fazer sentido no e do mundo. Sendo assim, é um construto que gera novas questões a respeito de assuntos fundamentais relacionados à comunicação e à cognição humana.

Algumas das implicações do uso do conceito de translinguagem são evidenciadas através das respostas dadas pelo conferencista às perguntas feitas por meio do chat, ao fim da apresentação. As perguntas são pertinentes ao assunto e geram respostas valiosas que possibilitam a discussão de alguns pontos referentes à translinguagem que não foram diretamente abordados na palestra.

Uma dúvida que aparece ao final da conferência é muito comum em discussões sobre translinguagem, e se refere a como esta concepção se diferencia da noção de code-switching, bastante popular na literatura sobre bilinguismo. Code-switching diz respeito às alternâncias entre as línguas de um bi/multilíngue em episódios comunicativos específicos (LI WEI, 2018). Esse processo acontece de forma espontânea entre bi/multilíngues ao se comunicarem com outros indivíduos que compartilham das mesmas línguas. Apesar de haver alguma sobreposição entre os conceitos, Li Wei afirma que a translinguagem difere de code-switching pois ela é uma abordagem analítica que permite investigar as práticas nas quais ele tem interesse, tendo como foco a forma como indivíduos usam diferentes recursos linguísticos, semióticos e cognitivos para produzir sentidos, indo além dos limites das línguas nomeadas. De acordo com o professor, o conceito de code-switching não dá conta desses estudos, pois as investigações feitas através dele focam em análises estruturais ou funcionais do processo de integrar sistemas gramaticais diferentes em uma unidade coerente e nos propósitos dessas trocas (LI WEI, 2018). Dessa forma, o linguista declara que os dois conceitos podem coexistir e serem usados em contextos distintos, pois eles têm propósitos diferentes.

Outra dúvida concerne as aplicações práticas do conceito no contexto educacional da aprendizagem de línguas. O conferencista afirma que há um interesse crescente no uso da translinguagem com uma abordagem pedagógica. Li Wei declara que a maior consequência do uso dessa perspectiva no âmbito pedagógico seria nas políticas educacionais monolíngues, pois essa abordagem vai contra elas. Enquanto monolíngues usam o seu repertório linguístico completo no aprendizado e na avaliação, bilíngues podem raramente fazer o mesmo. Essa mudança poderia beneficiar a aprendizagem, a identidade e a subjetividade de falantes de línguas minoritárias, por exemplo. Através dessa perspectiva, a criatividade do multilíngue é destacada pois ela valoriza a sua habilidade de quebrar limites entre as línguas nomeadas e variedades linguísticas e usar as suas habilidades para questionar, problematizar e articular ideias (LI WEI, 2011).

Em síntese, é através do uso da translinguagem que bilíngues e multilíngues podem ter a oportunidade de usar todo o seu repertório linguístico na sala de aula para construir o seu processo de aprendizagem. Esse conceito é especialmente importante em contextos onde há uma língua minoritária, que costuma ser apagada, ou até proibida de ser usada, em favor da língua maioritária do lugar. Como muito bem colocado por Li Wei, o principal objetivo ao se aprender uma língua adicional é se tornar bilíngue ou multilíngue e não um monolíngue naquela língua. Assim, é através da valorização de todos os recursos linguísticos trazidos pelos indivíduos que uma educação mais justa pode ser proporcionada para bilíngues de diferentes contextos. 


\section{REVISTA DA ABRALIN}

Rica em questionamentos, a fala de Li Wei nos convida a refletir sobre as concepções de linguagem e língua existentes, bem como sobre as implicações da perspectiva da translinguagem para os estudos sobre bi/multilinguismo e para contextos educacionais. Ao utilizar o conceito de translinguagem, podemos repensar a comunicação bi/multilíngue como uma prática complexa que emprega diversos recursos linguísticos e não linguísticos e que não pode ser limitada apenas pelas línguas faladas pelos indivíduos.

\section{REFERÊNCIAS}

BAKER, C. Foundations of Bilingual Education and Bilingualism. Multilingual Matters: Clevedon, 2001. 484p.

GARCÍA, O. Bilingual education in the 21st century: A global perspective. Malden/Oxford: Wiley/Blackwell, 2009.

GARCÍA, O.; WEI, L. Translanguaging: Language, bilingualism and education. London: Palgrave Macmillan, 2014. 162p.

LI WEI. (Ed.) The Bilingualism Reader. London/New York: Routledge, 2000. 560p.

LI WEI. Moment analysis and translanguaging space: Discursive construction of identities by multilingual Chinese youth in Britain. Journal of Pragmatics, 43, p. 1222-1235, 2011.

LI WEI; MOYER, M. (Eds.) The Blackwell Guide to Research Methods in Bilingualism and Multilingualism. Oxford: Blackwell, 2008. 424p.

LI WEI. Translanguaging and Code-Switching: what's the difference? em OUPblog, 2018. Disponível em:

<https://blog.oup.com/2018/05/translanguaging-code-switching-difference/>. Acesso em: 12 de ago. de 2020.

TRANS-ING Language and Cognition: Debates and Directions of Translanguaging Research. Conferência apresentada por Li Wei [s.l., s.n], 2020. 1 vídeo (57min:26s). Publicado pelo canal da Associação Brasileira de Linguística. Disponível em https://www.youtube.com/watch?v=RxBBaRaO9jk. Acesso em: 31 jul.2020. 